\title{
MOLECULAR MODELING-GUIDED DISCOVERY OF NOVEL TANKYRASE INHIBITORS
}

\section{E.V. Radchenko' ${ }^{1}$, V.P. Berishvili', A.N. Kuimov ${ }^{2}$, A.E. Voronkov ${ }^{1,3}$ and V.A. Palyulin1}

${ }^{1}$ Department of Chemistry, Lomonosov Moscow State University, 119991, Russia, Moscow.

${ }^{2}$ A.N. Belozersky Institute of Physico-Chemical Biology, Lomonosov Moscow State University, 119991, Russia, Moscow.

${ }^{3}$ Digital BioPharm Ltd., 0768, Norway, Oslo, Hovseterveien 42 A, H0301.

DOI: 10.19163/MedChemRussia2021-2021-70

E-mail:genie@qsar.chem.msu.ru

Tankyrase enzymes (TNKS) belonging to the poly(ADP-ribose) polymerase (PARP) superfamily are a promising target in the search for potential anti-cancer agents. Using the molecular docking and machine learning-based virtual screening techniques combined with the physico-chemical and ADMET profile prediction as well as molecular dynamics simulations, we have identified a number of candidate compounds in a subset of the ZINC database. Out of seven compounds biologically evaluated in vitro for their inhibition of the TNKS2 enzyme using immunochemical assay, one compound has shown good inhibitory activity with $I C_{50}$ value less than $10 \mathrm{nM}$. Relatively simple scores based on molecular docking or MM-PBSA methods proved unsuitable for predicting the effect of structural modification or for accurate ranking of the compounds based on their binding energies. On the other hand, the molecular dynamics simulations and Free Energy Perturbation (FEP) calculations allowed us to further decipher the structure-activity relationships and retrospectively analyze the docking-based virtual screening performance. This approach can be applied at the subsequent lead optimization stages.<smiles>O=C(NCCNC(=O)c1cnccn1)c1ccc(-c2cc3ccccc3oc2=O)cc1</smiles>

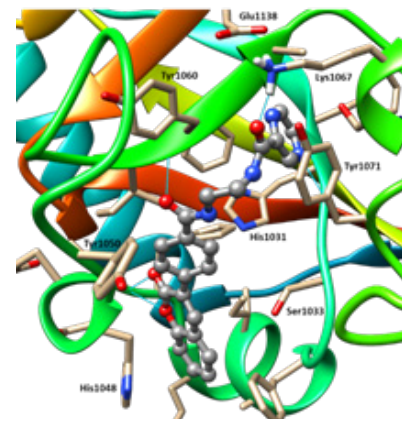

This study was supported by the Russian Foundation for Basic Research (project no. 18-515-80028) under the BRICS STI cooperation program.

\section{References}

[1] V.P. Berishvili, A.N. Kuimov, A.E. Voronkov, E.V. Radchenko, P. Kumar, Y.E. Choonara, V. Pillay,

A. Kamal, V.A. Palyulin, Molecules, 2020, 25, 3171. 